\title{
Socio-demographic and clinical characteristics of psoriatic patients attended dermatology clinics in Mosul city
}

\author{
Salah Ali Al-Ashow*, Bassam Abd Al-Mobdi Al-Neema** \\ * Department of Medicine, ** Department of Community Medicine, \\ College of Medicine, University of Mosul.
}

(Ann. Coll. Med. Mosul 2012; 38 (2): 23-27).

Received: $29^{\text {th }}$ May 2011; Accepted: $7^{\text {th }}$ Dec. 2011.

\section{ABSTRACT}

Background: Psoriasis affects $0.5-0.7 \%$ of Iraqi people making it one of the significant dermatological problems. Despite the extent of this problem, little information regarding its epidemiology is available in this country.

Objectives: To define the socio-demographic and clinical characteristics of psoriatic patients attended dermatology clinics in the four major governmental hospitals in Mosul city.

\section{Patients and methods:}

Study setting: Dermatology clinics in the 4 major governmental hospitals (Al- Jamhouri, Ibn Sina, Al-Salam, and Al- Mosul) in Mosul.

Study design: Cross-sectional study.

Study period: $1^{\text {st }}$ October 2101 to $25^{\text {th }}$ of February 2011.

Participants: Patients with psoriasis of both sexes, and all ages, who attended the dermatological clinics. Each patient was subjected to detailed history and clinical examination. Data collection form included various demographic and clinical characteristics.

Results: The sample of the study included 154 patients with psoriasis, comprising $50.6 \%$ males ranging in age from 3-62 years. The mean age $\pm S D$ at presentation was $30.2 \pm 15.1$ years; the mean age $\pm S D$ at onset was $22.8 \pm 12.0$ years. The mean duration of the illness was 7.4 years. A unimodal distribution curve of age at onset was noticed with a peak at the third decade. Early onset of psoriasis before 30 years was significantly associated with family history. Severity of psoriasis was mild in 74 (48.1\%) of cases and it was more severe in elderly with longstanding disease. Itching and disfigurement were the main complaints especially the young and female patients. Plaque type (64.9\%) was the most common variant, arms (52.6\%) were the most commonly affected body site, and the scalp (27.9\%) was the most common initial site affected by psoriasis. Nail involvement was seen in 30 (19.5\%) patients especially fingernails.

Conclusions and recommendation: The study revealed that psoriasis is a heterogeneous disease affecting all ages, genders and socio-economic strata. Further researches to study the relationship and the impact of these characteristics on the life of sufferers is recommended.

الخلاصة

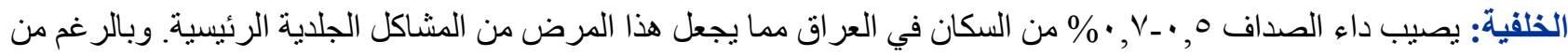

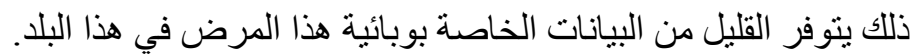
الأهداف: تحديد الصفات الاجتماعية والديموغر افية والسريرية لمرضى داء الصداف المراجعين لمستشفيات الموصل الأربعة

موقع الدراسة: عيادات الأمراض الجلدية في المستشفيات الأربعة الرئيسية (الجمهوري، ابن سينا، السلام والموصل) في مدينة 


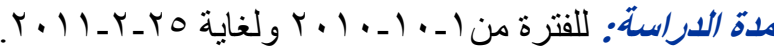

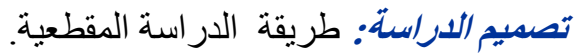

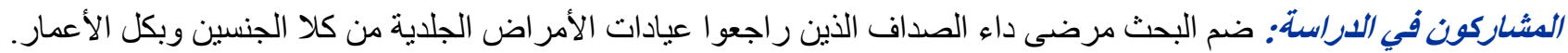

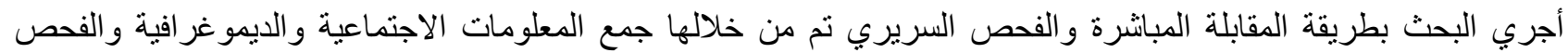
ألسريري للمريض. ألبض.

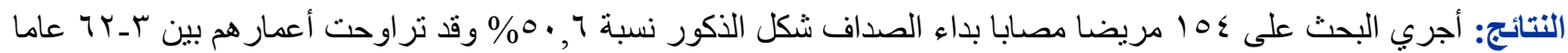

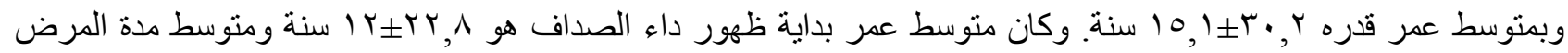

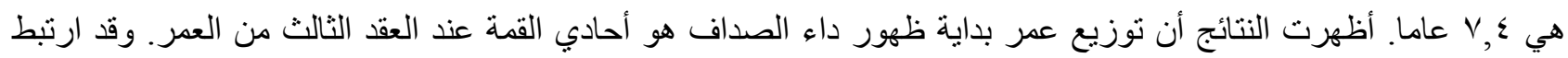

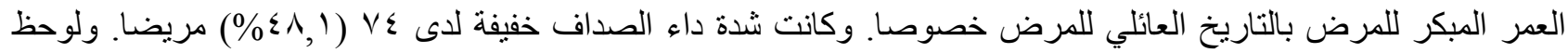

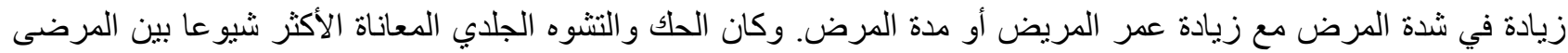

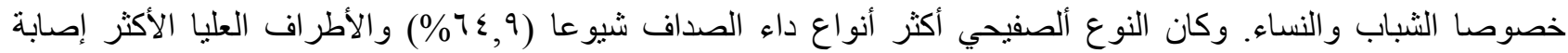

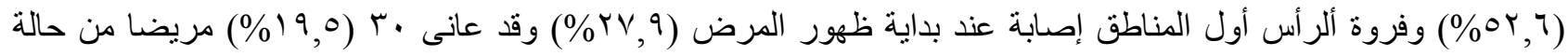

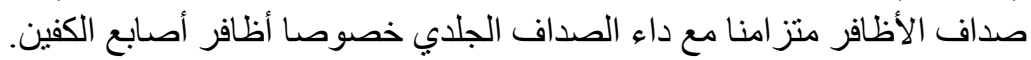

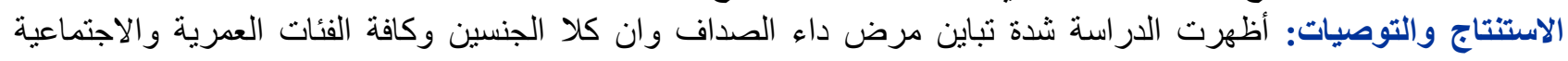
معرضة للإصابة بهذا المرض ويوصى بأجر اء المزيد من البحوث لدان استة العلاقة بين هذه الصفات ونأثنير ها على حياة المصابين.

$\mathrm{P}$ soriasis is a common, incurable, inflammatory cutaneous disease. According to National Psoriasis Association (NPA), 125 million people suffer from psoriasis worldwide. ${ }^{(1)}$ Psoriasis shows wide geographic variations in clinical features and prevalence, ranging from 3\% in Scandinavians to absent among Aborigines (natives of Australia). ${ }^{(2)}$ In Iraq, prevalence of psoriasis varies from $0.5 \%$ to $0.7 \%{ }^{(3,4)}$. This figure puts psoriasis in list of major dermatological problems in Iraq. Unfortunately, epidemiologic studies of psoriasis conducted in this locality do not parallel the magnitude of the problem. The scanty available epidemiologic data prompt to conduct this demographic and clinical study hoping that results will form a baseline data for health professionals, decision makers, and academics $^{(5)}$. The obtained data will also offer a baseline for study on quality of life of patients who suffer from psoriasis.

\section{Objectives}

1. To define the socio-demographic characteristics of patients with psoriasis.

2. To demonstrate the clinical characteristics of patients in the study sample.

\section{PATIENTS AND METHODS}

This work was carried out as a cross-sectional study on patients with psoriasis who attended dermatology clinics in four major hospitals (in Mosul (Al-Jumhuri, Al-Salam, Ibn Sina and Al-
Mosul General Hospitals). The study was conducted during the period of $1^{\text {st }}$ October 2010 to $25^{\text {th }}$ January 2011.

After identifying eligible patients with psoriasis and invited to participate in the study, each patient was exposed to the following:

- Oral consent.

- Filling demographic data form (age, gender, education level, occupation, marital status, and socioeconomic status).

- Assessing of clinical information (age at onset, duration of disease, site of lesions, and the types of psoriasis).

- Determining clinical severity using the extent of body surface area involved by psoriatic lesions. The area of lesions covered by single palm will be equal to $1 \%$ of body surface area involvement (BSA). The disease will be classified into mild ( $<5 \%$ BSA), moderate (5$10 \% \mathrm{BSA})$ and severe $(>10 \% \mathrm{BSA})^{(6)}$.

Descriptive statistical methods were used to summarize and tabulate the different sociodemographic and clinical parameters of the studied sample. Inferential statistics was performed by the use of Z- test of one proportion for dichotomous variables (gender, age at onset and family history of psoriasis).The other multiple variables were assessed simply by the percentages. The significance was considered at (0.05). Statistical processing of data were conducted by the use of 
statistical package SPSS ver.13 (SPSS Inc, Chicago ILL).

\section{RESULTS}

During study period the proportional morbidity rate of psoriasis from all the cases recorded in the consultation clinics of dermatology was $5.26 \%$.

A total of 154 patients suffering from psoriasis agreed to participate and were enrolled in the current study. They were 78 (50.6\%) males and 76 (49.4\%) females with male to female ratio about 1:1.

Minimum and maximum age at presentation were 3 years and 62 years respectively with mean and standard deviation of $30.2 \pm 15.1$ years. After tabulating the age into 15 years intervals, highest proportion was found among age group 15-29 years (36.4\%).

The demographic characteristics of the studied sample were shown in Table 1.

Table 1. Socio-demographic characteristics of psoriasis in study subjects.

\begin{tabular}{|c|c|c|c|}
\hline Characteristics & Number & $\%$ & P-value \\
\hline \multicolumn{4}{|l|}{ Age group } \\
\hline 1-14 year & 28 & 18.2 & \\
\hline 15-29 year & 56 & 36.4 & \\
\hline 30-44 year & 42 & 27.3 & \\
\hline $45+$ year & 28 & 18.2 & \\
\hline \multicolumn{4}{|l|}{ Gender } \\
\hline Male & 78 & 50.6 & \multirow{2}{*}{0.936} \\
\hline Female & 76 & 49.4 & \\
\hline \multicolumn{4}{|l|}{ Marital status } \\
\hline Single & 66 & 42.9 & \\
\hline Married & 84 & 54.5 & \\
\hline Widow & 4 & 2.6 & \\
\hline \multicolumn{4}{|c|}{ Occupational-Social class* } \\
\hline Class I & - & & \\
\hline Class II & 24 & 15.6 & \\
\hline Class III & 72 & 46.8 & \\
\hline Class IV & 48 & 31.2 & \\
\hline Class V & 10 & 6.5 & \\
\hline \multicolumn{4}{|l|}{ Educational level } \\
\hline Illiterate & 24 & 15.6 & \\
\hline Primary & 62 & 40.3 & \\
\hline Secondary & 48 & 31.1 & \\
\hline High & 20 & 13.0 & \\
\hline \multicolumn{4}{|l|}{ Residence } \\
\hline Urban & 118 & 76.6 & \\
\hline Rural & 24 & 15.6 & \\
\hline $\begin{array}{l}\text { Recent } \\
\text { urbanization }\end{array}$ & 12 & 7.8 & \\
\hline
\end{tabular}

${ }^{*}$ Class I= professional, class II= intermediate, class III=skilled, class IV= partially skilled, \& class $\mathrm{V}=$ unskilled $^{(19)}$.
The results revealed that largest proportion of the studied sample were from class III, smallest proportion were from class $\mathrm{V}$, while none from class I. The largest proportion of patients had a low education in comparison, only $15 \%$ of patients were graduates. The analysis of educational level showed that $90 \%$ of illiterate were females while $70 \%$ of graduate were male patients. About $3 / 4$ of the patients reside city while the rest quarter were either inhabitants of rural areas or recently immigrated to urban areas.

The clinical characteristics of the studied sample are shown in Table 2. In this study, psoriasis onset ranged from 3 to 50 years with mean and SD of $22.8 \pm 12.0$ years. Fifty-three patients (34.4\%) had a positive family history of psoriasis in one or more of their relatives was statistically very highly significant $(p$-value $=0.001)$.

The duration of the disease extended from recently diagnosed cases to 33 years with mean of 7.4 years. The result revealed that around $2 / 3$ of patients suffered from psoriasis for a period less than 5 years while in the remaining $1 / 3$ of patients duration of illness exceeded 5 years.

Based on percentage of body surface area involved by psoriatic lesions, patients were classified as mild in $74(48.1 \%)$ of cases, moderate in 54 (35.1\%), and severe in 26 (16.8\%).

Table 2. Clinical characteristics of psoriasis in the study subjects.

\begin{tabular}{|c|c|c|c|}
\hline Characteristics & Number & $\%$ & P-value \\
\hline \multicolumn{3}{|l|}{ Age at onset } & \\
\hline$<30$ year & 108 & 70.1 & \multirow{2}{*}{0.001} \\
\hline $30+$ & 46 & 29.9 & \\
\hline \multicolumn{3}{|c|}{ Duration of psoriasis } & \\
\hline$<1$ year & 36 & 23.3 & \\
\hline 1-5 year & 54 & 35.1 & \\
\hline$>5$ year & 64 & 41.6 & \\
\hline \multicolumn{3}{|c|}{ Family history of psoriasis } & \\
\hline Negative & 101 & 65.6 & \multirow{2}{*}{0.001} \\
\hline Positive & 53 & 34.4 & \\
\hline \multicolumn{3}{|l|}{ Chief complaint } & \\
\hline Itching & 68 & 44.2 & \\
\hline Disfigurment & 52 & 33.8 & \\
\hline Pain & 6 & 3.9 & \\
\hline Discomfort & 28 & 18.2 & \\
\hline \multicolumn{3}{|c|}{ Severity of cutaneous lesions } & \\
\hline Mild & 74 & 48.1 & \\
\hline Moderate & 54 & 35.1 & \\
\hline Severe & 26 & 16.8 & \\
\hline
\end{tabular}


Mild to moderate itching was the main complaint of $68(44.2 \%)$ of patients and $52(33.8 \%)$ complain from cosmetic disfigurement.

Discomfort was reported by 28 patients (18.2\%) and pain (due to arthralgia or cracked skin) was the least frequent complaint and it was suffered by only 6 (3.9\%) cases. The most important determinant of itching was duration of diseases while disfigurement was more among females and in those whose lesions involving visible and sensitive sites (like genitalia).

The results of clinical examination are shown in Table 3. The most frequent variants of psoriasis were plaque 100 cases $(64.9 \%)$, guttate in 24 (15.6\%), palmoplanter in $18(11.7 \%)$, flexural in 6 (3.9\%), generalized pustular in $3(1.9 \%)$, and erythroderma in $3(1.9 \%)$.

Table 3. Variants and area of body commonly affected with psoriasis.

\begin{tabular}{|c|c|c|}
\hline Characteristics & Number & $\%$ \\
\hline \multicolumn{3}{|l|}{ Variants of psoriasis } \\
\hline Plaque & 100 & 64.9 \\
\hline Guttate & 24 & 15.6 \\
\hline Palmoplanter & 18 & 11.7 \\
\hline Flexural & 6 & 3.9 \\
\hline Generalize pustular & 3 & 1.9 \\
\hline Erythroderma & 3 & 1.9 \\
\hline \multicolumn{3}{|l|}{ Nail involvement } \\
\hline Absent & 124 & 80.5 \\
\hline Present & 30 & 19.5 \\
\hline \multicolumn{3}{|l|}{ Site of cutaneous lesions* } \\
\hline Arms & 81 & 52.6 \\
\hline Legs & 67 & 43.5 \\
\hline Trunk & 24 & 15.6 \\
\hline Scalp & 16 & 10.4 \\
\hline Hands & 12 & 7.8 \\
\hline Genitalia & 8 & 5.2 \\
\hline Soles & 7 & 4.5 \\
\hline Face & 3 & 1.9 \\
\hline \multicolumn{3}{|l|}{ Site of initial lesion } \\
\hline Scalp & 43 & 27.9 \\
\hline elbow & 33 & 21.4 \\
\hline leg & 21 & 13.6 \\
\hline feet & 20 & 13.0 \\
\hline palms and soles & 15 & 9.7 \\
\hline arms & 10 & 6.5 \\
\hline trunk & 6 & 3.9 \\
\hline axillae & 3 & 1.9 \\
\hline
\end{tabular}

*Percentage may exceed $100 \%$ because psoriasis can affect more than one site in the same patient at the same time.
The nails were involved in $30(19.5 \%)$ cases. Among the 30 patients with nail changes 16 (10.4\%) had their fingernails involved, 9 (5.8\%) suffered from toenails psoriasis while the remaining 5 (3.2\%) had both finger and toe nails involved.

Six (3.9\%) patients complained from arthralgia and in 2 (1.3\%) frank arthritis was elicited.

The most common sites affected by psoriasis were the arms 81 (52.6\%), followed by legs 67 (43.5\%), trunk 24 (15.6\%), scalp 16 (10.4\%), hands $12(7.8 \%)$, genitalia $8(5.2 \%)$, soles 7 $(4.5 \%)$, and the least were the face which was involved in $3(1.9 \%)$.

Scalp was the most common initial site affected by psoriasis accounting for $27.9 \%$ of the patients followed by elbows (21.4\%), knees (13.6\%), feet (13\%), palms and soles (9.7\%), arms (6.5\%), trunk (3.9\%), and axillae (1.9\%).

\section{DISCUSSION}

The present study showed that $6.5 \%$ of patients were under 10 years and the percentage raised to $18.2 \%$ of the sample in those 15 year old or younger. This result was consistent with the findings of a survey on childhood psoriasis conducted in Kuwait $^{(7)}$. The mean age at presentation (30.2 years) found in the current study was in agreement with previous epidemiologic studies conducted locally ${ }^{\left({ }^{(8)}\right.}$ and internationally ${ }^{(9)}$.

There is remaining controversy regarding psoriasis gender preponderance and it lies between no difference ${ }^{(2)}$ to male preponderance ${ }^{(1)}$. The current study supports the opinion of equal male and female ratio which was 1.03:1.00.

Although psoriasis may occur from birth to advanced ages, most of reviewed literature ${ }^{(10)}$ including the present study suggested that third decade to represent peak of onset. Determination of age at onset is a problematic issue for researchers due to the followings: first, it relies on patient 's recall; second, date of first diagnosis doesn't reflect the onset as many patients suffer long time before seeking medical care ${ }^{(11)}$.

Smith et $\mathrm{al}^{(11)}$, postulated that psoriasis has a bimodal peak of activity. They stated that the bimodal distribution in psoriasis incidence represented two clinical presentations of psoriasis, so called type I (genetically determined) and type II (environmentally determined). The current study 
did not show any indication of bimodal prevalence. The distribution of age at onset of psoriasis in the current study showed only one peak in the age group 20-29 years.

Familial clustering in psoriasis had been observed for many years ${ }^{(12)}$. A positive family history in $34.4 \%$ of the studied sample provided another support of this concept. Moreover, it confirmed the important role of genetics in the etiology of psoriasis especially in those with early onset ${ }^{(13)}$. This figure was also in agreement with the figure reported few years ago in the same locality (Mosul city) which was (38.5\%). ${ }^{(8)}$

The clinical manifestations of psoriasis are heterogeneous, ranging from limited to very extensive disease ${ }^{(14)}$. The severity yielded from studied sample was compared with a recent study of psoriatic patients selected from USA population via random digit dialing which show the followings: $57.4 \%$ had mild psoriasis, $38.8 \%$ had moderate, and the remaining were considered as severe cases $^{(15)}$. The present study to some extent is in agreement with US study. Minor difference may be due to variation in the severity assessment between researchers (due to lack of standardized severity assessment method) ${ }^{(6)}$ and variation in the course of disease (due to the nature of psoriasis to wax and wane) $)^{(16)}$.

Nail changes are relatively common in psoriasis yet often an overlooked aspect of the disease ${ }^{(17)}$. Findings in this study reflected similar results as reported in previous literatures. A notable difference was noticed in the frequency of nail involvement between the current study (19.5\%) and other studies $(58 \%)^{(18)}$. This discrepancy may be due to difference in case definition (minor roughing of nail, which was omitted in the current research while considered significant change by other researchers) or difference in population (percentage of severe cases).

In conclusion, the study revealed that psoriasis is a heterogenous disease affecting all ages, genders and socio-economic strata. Further researches to study the relationship of these characteristics on the life of sufferers are recommended.

\section{REFERENCES}

1. Raychaudhuri SP, Farber EM. The prevalence of psoriasis in the world. J Eur Acad Dermatol Venereol 2001; 15:16-17.
2. Chandaran V, Raychaudhuri SP. Geoepidemiology and environmental factors of psoriasis and psoriatic arthritis. J Autoimmun 2010;314-21.

3. Abdul Majeed AZ. The prevalence of skin diseases in Ninavah Governorate. MSc Thesis, University of Mosul, College of Medicine, Department of Community Medicine; 2002.

4. Al-Rubiay KK. Dermato-epidemiology: A household survey among two urban area in Basrah city, Iraq. Int J Dermatol 2006;4-16.

5. Willam HC. Epidemiology of Skin Diseases. In: Burn T, Breathnack S, Cox N, Griffiths C, editors. Rook's Textbook of Dermatology. $8^{\text {th }}$ edition. Singapore: Willy-Blackwell; 2010. p. 1-21.

6. Feldman SR, Krueger S. Psoriasis assessment tools in clinical trials. Ann Rheum Dis 2005;64:65-8.

7. Al-Fouzan AS, Nanda A. A survey of childhood psoriasis in Kuwait. Pediat Dermatol 1994;11:116-9.

8. Thiab TM. Risk factors of psoriasis in Ninavah Governorate. MSc thesis. University of Mosul, College of Medicine, Department of Community Medicine;2005.

9. Neimann Al, Porter SB, Gelfland JM. The epidemiology of psoriasis. Expert Rev Dermatol 2006;1:63-75.

10. Gudjonssen JR, Elder JL. Psoriasis. In: Wolf K, Austen KF, Freedberg IM, editors. Fitzpatrick's Dermatology In General Medicine. $7^{\text {th }}$ ed. New York: McGraw Hill; 2008. p.169-93.

11. Smith AE, Kassab JY, Beer WF. Bimodality in age of onset of psoriasis, in patients and their relatives. Arch Dermatol 1993;186:181-6.

12. Naldi L, Peli L, Parzzini F. Familial history of psoriasis, stressful events and recent infectious for first epsoid of acute psoriasis: result of case controlled study. British Journal of Dermatol 2001;44:433-38.

13. Ferrandiz C, Pujot R, Garcia-Patos V. Psoriasis of early and late onset: A clinical and epidemiologic study from Spain. J Am Acad Dermatol 2002;46:867-73.

14. Naldi L. Gambini D. The clinical spectrum of psoriasis. Cl Dermatol 2007;46:867-73.

15. Gelfland RM, Feldmann SR, Stern RS. Determination of quality of life in patients with psoriasis: A study from US population. J Am Acad Dermatol 2004; 51: 704-8.

16. Psoriasis. In: James W, Berger TG, Elston DM, editors. Andrew's Diseases of Skin. $10^{\text {th }}$ edition. Canada: WB Saunders; 2006.p.193-202.

17. Williamson L, Dalbeth T, Dockerty JL. Extended report nail disease in psoriatic arthritis-clinically important, potentially treatable and often overlooked. Rheumatol 2004;43:790-4.

18. Ahmed I, Nasreen S. Frequency and pattern of nail changes in patients with psoriasis vulgaris. J Pak Ass Dermatol 2009; 19:194-9.

19. Al-Youzbaki DB. Cultural Sociology for Health \& Illness. $1^{\text {st }}$ edition. Mosul: Dar Ibn Al-Atheer; 2007. p.90. 